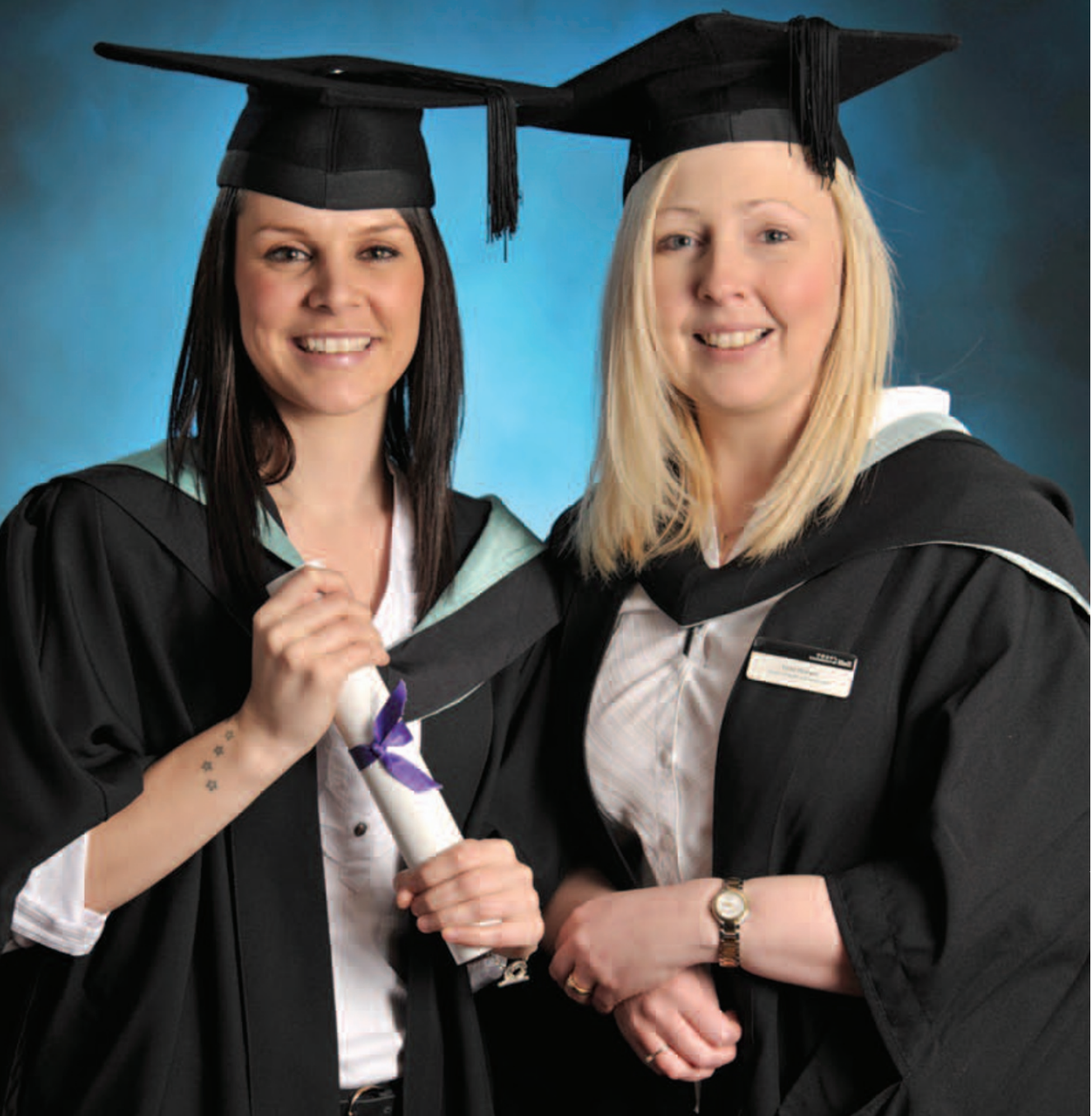

\section{AVRIL IS A SHINING EXAMPLE TO DENTAL NURSES}

Avril Ware is the first student in the Yorkshire region to attain the Foundation Degree in Post-qualifying Dental Nursing Practice. Avril, 24, graduated from the University of Hull, which is only the second institution in the country to offer the qualification (the University of Northampton also offers an FdSc in Dental Nursing).

The foundation degree offers qualified dental nurses the chance to extend and enhance their skills in a range of disciplines.

Avril successfully juggled her studies with her work as a practice manager for ADP Dental in Longhill, east Hull.

'I am now applying to dental school and places are really competitive', said Avril, who graduated as part of the University of Hull's winter degree ceremonies in January. 'This foundation degree will help me stand out from the other applicants. I would recommend the course to others who are looking to increase their knowledge and skills in dental nursing or like me want to take the next step into areas such as dental therapy.'

The University of Hull offers the Foundation Degree in Post-qualifying Dental Nursing Practice over two years on a full-time basis or part-time up to four years and a variety of pathways are available to include areas of extended practice such as dental radiography, dental sedation and special care.

'Avril is a shining example of what students can achieve', said lecturer Victoria Hewson (pictured, right, with Avril). 'We hope other dental nurses see this as an inspiration to further enhance their own professional development.'

Eighteen students are now studying towards their foundation degree at Hull.

Further details about the course can be found at: http://www2.hull.ac.uk/fhsc/courses/ foundationdegrees/dentalnursepractice.aspx

Look out for the annual DCP course directory in the summer issue of Vital.

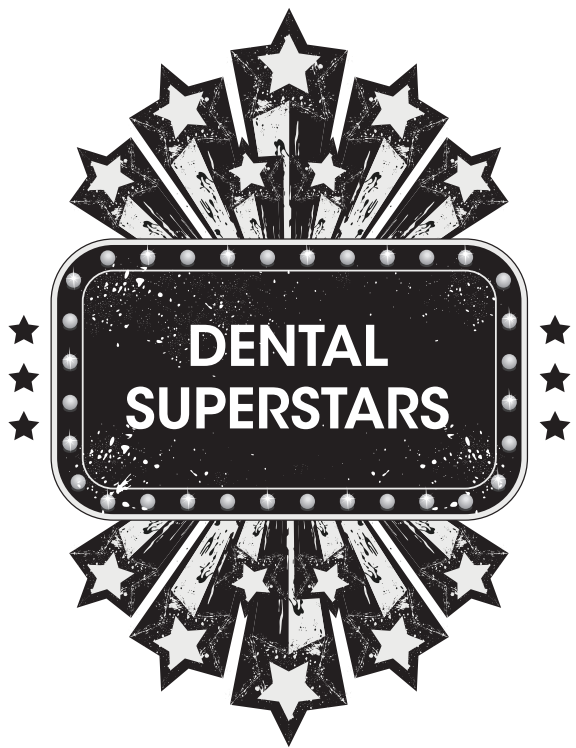

Fiona Ellwood was presented with the 2011 British Association of Dental Nurses (BADN) Outstanding Contribution to Dental Nursing Award at the sixth BDA Honours and Awards Dinner at the Chancery Court Hotel in London in November. Fiond became a BADN member when she qualified as a dental nurse in 1986 and is currently a Director of the Dental Business Academy, leading their educational sector.

s. tooth+, a small private dental practice in Stirling, was named the UK's Best Dental Practice at The Dentistry Awards 2011 held in

the Athena, Leicester. The practice was also named Scotland's Best Dental Practice and owes its glory to its customer-focused approach to dentistry, providing a comfortable, relaxed environment for patients.

Dartford Road Dental Centre in Kent has achieved the British Dental Association Good Practice Scheme award. Practice Manager Kim Bennett spent a year working towards the award on behalf of the practice team and their patients.

BADN Past President and Chairman of Council Angie McBain received an MBE in the New Year Honours list for services to dental nursing. Angie is currently Lead Dental Nurse Tutor for Barnfield College. London and DCP Tutor for the East of England Deanery.

Seventy-eight percent of students from the BDA Oral Health Education course who took the NEBDN OHE exam in September 2011 passed. Special congratulations from the BDA go to Cinzia Pickett who was awarded the only distinction out of 169 candidates, and to Lucy Goldstraw who was one of four students to be awarded a merit.

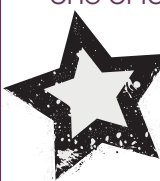

Caroline Clitter was presented with the prestigious $\mathrm{Dr}$ Gerald Leatherman Award at the British Society of Dental Hygiene and Therapy's (BSDHT's) Oral Health Conference and Exhibition in Bournemouth in November. The late Dr Leatherman was a pioneer of preventive dentistry in the UK and dedicated his professional life to raising the profile of the dental hygienist. 